\title{
Long-Chain Polyunsaturated Fatty Acid Supplementation in Infancy Reduces Heart Rate and Positively Affects Distribution of Attention
}

\author{
JOHN COLOMBO, SUSAN E. CARLSON, CAROL L. CHEATHAM, KATHLEEN M. FITZGERALD-GUSTAFSON, AMY KEPLER, \\ AND TASHA DOTY \\ Department of Psychology [J.C.], University of Kansas, Lawrence, Kansas 66045; Department of Dietetics and Nutrition [S.E.C., A.K., \\ T.D.], Hoglund Brain Imaging Center [K.M.F.G.], University of Kansas Medical Center, Kansas City, Kansas 66160; Department of \\ Psychology [C.L.C.], University of North Carolina, Chapel Hill, North Carolina 27599
}

\begin{abstract}
A double-blind, randomized, controlled, parallelgroup prospective trial was conducted to determine whether a doseresponse existed for four different levels of docosahexaenoic acid (DHA) supplementation on the cognitive performance of infants. A total of 122 term infants were fed one of four different formulas varying in their DHA composition $(0.00,0.32,0.64$, and $0.96 \%$ of total fatty acids as DHA) from birth to 12 mo. The three DHAsupplemented formulas also contained $0.64 \%$ of total fatty acids as arachidonic acid (ARA, 20:4n-6). Infants were tested at 4, 6, and 9 mo of age on a visual habituation protocol that yielded both behavioral and psychophysiological indices of attention. Infants in all DHA+ARA-supplemented conditions had lower heart rates than those in the unsupplemented condition; there was no dose-response for this effect. The distribution of time that infants spent in different phases of attention (a cognitive index derived from the convergence of behavioral and cardiac responses) varied as a function of dosage. Infants supplemented at the two lower DHA doses spent proportionately more time engaged in active stimulus processing than infants fed the unsupplemented formula, whereas infants fed the highest dose were intermediate and did not differ from any other group. (Pediatr Res 70: 406-410, 2011)
\end{abstract}

$\mathrm{T}^{\mathrm{h}}$ he CNS is highly enriched in docosahexaenoic acid (DHA, 22:6n-3) and arachidonic acid (ARA, 20:4n-6), but of these two fatty acids, only brain DHA content has been shown to vary as a result of postnatal dietary intake $(1,2)$. CNS DHA accumulates rapidly during the last intrauterine trimester and in the first $2 \mathrm{y}$ of life $(3,4)$. A number of randomized studies of DHA supplementation have been designed with the intent of understanding the functional consequences of increasing postnatal DHA exposure. The majority of these studies have measured visual acuity. In term infant studies, both positive $(5,6)$ and null $(7-9)$ effects of postnatal supplementation have been observed, with positive effects typically

Received November 16, 2010; accepted April 27, 2011.

Correspondence: Susan E. Carlson, Ph.D., Department of Dietetics and Nutrition, University of Kansas Medical Center, Kansas City, Kansas 66160; e-mail: scarlson@kumc.edu

Supported by Mead Johnson Nutrition, Evansville, IN. Supported also by the University of Kansas Medical Center and by the University of Kansas Intellectual and Developmental Disabilities Research Center, P30 HD002528. Supported in part by grant R01 HD047315 for analyses and preparation of the report.

J.C. and S.E.C. are occasional consultants for Mead Johnson Nutrition, but neither own stock in Mead Johnson or its affiliates. C.L.C., K.M.F.-G., A.K., and T.D. declare no conflict of interest. manifest as an accelerated developmental function for visual acuity during the first year of life.

Learning and cognition are also outcomes of interest given the large amount of DHA that accumulates in the brain, relative to other organs. Indeed, DHA has been reported to affect learning and cognition in both animals $(10,11)$ and humans $(12,13)$. However, the results of studies using global assessments of early cognitive function (e.g. the Bayley Scales of Infant Development or childhood IQ tests, such as the Stanford Binet or Weschler tests) as outcomes of long-chain polyunsaturated fatty acid (LCPUFA) supplementation or status are mixed. Investigators have reported benefits on the Brunet-Lezine Scale $(14,15)$, the Bayley Scales (16), and the Weschler Primary Preschool Scale of Intelligence (17). Null effects have been reported with the Bayley Scales (18) and with the Stanford Binet (19). Both a recent systematic review (20) and a meta-analysis (21) concluded that the Bayley Scales of Infant Development are unaffected by LCPUFA supplementation.

More precise measures of cognition in infancy have long been available from techniques developed for experimental laboratory studies (22). Indeed, measures of attention in infancy tend to be more closely correlated with later cognitive function than outcomes on global tests of early development $(23,24)$. Moreover, higher DHA exposure in utero has been associated with first year behavior indicative of accelerated attentional development (25), suggesting a potential value for attention as a means of evaluating the effects of LCPUFA supplementation on cognition. Prior randomized clinical trials of postnatal DHA supplementation have not included measures of attention. Furthermore, no previous randomized trial has examined the possibility of a dose-response with respect to the effect of DHA on development, thus inhibiting progress toward the establishment of a standard for DHA intake or supplementation.

Here, we report the results of postnatal LCPUFA supplementation with three levels of DHA supplementation on a specific measure of developing cognition, i.e. infant attention

Abbreviations: ARA, arachidonic acid; AT, attention termination; bpm, beats per minute; DHA, docosahexaenoic acid; HR, heart rate; LCPUFA, long-chain polyunsaturated fatty acids; OR, orienting; $\mathbf{S A}$, sustained attention 
and learning in a visual habituation paradigm (26). Along with behavioral indices of attention during visual habituation, we assessed heart rate (HR) and the quality of attention through the conjunction of HR deceleration with visual fixation, which allows the calculation of HR-defined phases of attention (27). The inclusion of measures of HR within the cognitive paradigm also allowed for a test of the effects of specific LCPUFA supplementation in infancy on cardiac variables; the extant literature suggests that LCPUFAs (especially omega-3 fatty acids) may affect HR and HR variability through a number of candidate mechanisms $(28,29)$.

\section{METHODS}

Data reported here were for planned secondary outcomes specific to one of the two sites involved in the DIAMOND ( $D H A$ Intake And Measurement $O$ f $N$ eural Development) study (registered as NCT00753818 at www.clinicaltrials.gov), a double-masked, randomized, controlled, parallel-group prospective trial designed primarily to measure sweep visual-evoked potential acuity. The primary outcomes of this trial were red blood cell DHA and ARA in response to formula and visual acuity development. The results have been reported elsewhere, and the report includes a complete description of study design, growth, formula intake and tolerance, red blood cell DHA and ARA in response to formula, and adverse events (30).

Participants. The trial enrolled healthy, term, formula-fed, singleton-birth infants (37-42 wk gestation; 2490 to $4200 \mathrm{~g}$ birth weight) born in the Kansas City metropolitan area between September 3, 2003, and September 25, 2005. Exclusion criteria included the receipt of human milk within $24 \mathrm{~h}$ of randomization, conditions known to interfere with normal growth (e.g. low birth weight; metabolic anomalies) or development (e.g. maternal chronic infectious, metabolic or renal disease, or evidence of alcoholism or substance abuse), poor formula intake, or intolerance to cow's milk infant formula. Informed consent was obtained from all subjects and the study was approved by the Human Subjects Committee at the University of Kansas Medical Center.

Design and randomization. During the first week of life, infants were randomly assigned to one of four cow's milk-based term infant formulas, which varied only in LCPUFA content. Control infants were fed formula containing no DHA or ARA. Three groups received supplemented formulas varying in DHA. One group received $0.32 \%$ of fatty acids from DHA (17 $\mathrm{mg} / 100 \mathrm{kcal})$, a second received $0.64 \%(34 \mathrm{mg} / 100 \mathrm{kcal})$, and a third received $0.96 \%(51 \mathrm{mg} / 100 \mathrm{kcal})$. All three DHA supplemented formulas included $0.64 \%$ of fatty acids $(34 \mathrm{mg} / 100 \mathrm{kcal})$ from ARA. DHA was derived from single-cell algal oils; ARA from fungal oils (Martek Biosciences, Columbia, MD). Blood level analyses were conducted on the four groups for DHA at 4 and 12 mo of age and have been reported elsewhere (30).

Randomization was performed by and held exclusively by the study sponsor during the conduct of the research. Each of the four formulas had two different codes, for a total of eight codes. All personnel recruiting infants, parents or guardians, researchers, study monitors, and pediatricians were blind to the infants' study formula group allocation. Infants were fed the study formulas for the first 12 mo without limits. Gender was balanced across all groups.

Procedures. Infants were evaluated at the study site at 4, 6, and 9 mo of age on a visual habituation protocol that was augmented with simultaneous measurement of HR. In visual habituation, the infant's visual and cardiac responses are assessed to repetitive stimulus presentations; the decline in responses to the stimulus is generally interpreted to indicate learning of the stimulus. Details of the testing situation, stimuli, and recording of infant looking are reported at length elsewhere $(25,31)$. The stimuli used in habituation tests were static color presentations of adult faces, chosen from a set used in previous research. Infants were habituated to one face at each visit, in a session lasting 5 to $15 \mathrm{~min}$ in length. The face stimuli used in the study were counterbalanced across ages, so that no infant saw the same stimulus twice.

Testing sequence. A 20-30 s baseline period was conducted before the start of the session, during which HR was collected with no stimulus present. Infants were then habituated to static visual stimuli using an infant-controlled sequence (32), with a criterion of two consecutive looks at a 50\% decrement from the previous longest look and a "floating-point" criterion (33). A valid fixation was defined as a look of $1 \mathrm{~s}$ or more in duration; fixations were considered to be terminated when the infant looked away for $1 \mathrm{~s}$ or more (34). The stimulus was removed after termination of a fixation, and a subsequent interstimulus period of $2 \mathrm{~s}$ ensued.

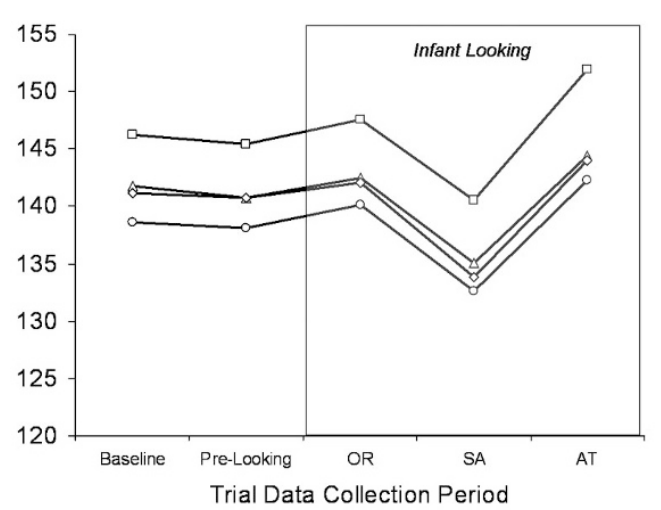

Figure 1. Mean HR (collapsed across age) for four formula groups at critical points of interest during the habituation task. Squares represent $0.0 \%$ DHA/ $0.0 \%$ ARA (unsupplemented controls); circles represent $0.32 \%$ DHA/0.64\% ARA; triangles represent $0.64 \%$ DHA/0.64\% ARA; and diamonds represent $0.96 \%$ DHA/0.64\% ARA.

Measurement of HR. HR was measured with shielded $\mathrm{Ag}-\mathrm{AgCl}$ electrodes placed on either side of the infant's chest and grounded with an unshielded electrode on the abdomen. The infant's ECG (EKG) was digitized at $250 \mathrm{~Hz}$ sample rate. The data acquisition interface also received input from the microcomputer that controlled the timing and presentation of stimuli so that HR could be synchronized with stimulus events and the coding of fixations.

Data reduction and statistical treatment. The time stamp of each infant's $\mathrm{R}$-wave was derived from the digitized EKG and synchronized with time stamps from stimulus events and infant behaviors. Along with the calculation of infant HR during the session, this protocol capitalizes on the fact that infants typically show HR deceleration while looking. This deceleration has been used to derive different types of attention during looking (35); the actual decelerative phase is called sustained attention (SA) and has been shown to reflect active engagement with, and processing of, the stimulus (35). The period preceding SA reflects simple orienting (OR) to the stimulus, and the period after SA reflects disengagement from the stimulus (attention termination, or AT). The derivation of these phases is explicated in detail elsewhere (31). For our purposes, the proportion of time spent in SA was the measure of interest. For purposes of brevity, analyses for OR and AT are not shown here (they were unaffected by formula), but these phases are represented in Table 3 and Figure 1.

Statistical methods. As a whole, the trial was powered for the primary outcomes of visual acuity (30). HR and looking variables from the habituation session were subjected to mixed-model factorial analyses (using PASW Statistics 17.0, formerly SPSS) using fixed factors of formula (4) and age (3). Age was entered into the model as a repeated factor, subjects as a random factor, and covariance was left unstructured. This analysis uses all available data in longitudinal applications, while allowing for simultaneous age comparisons, assessment of age $\times$ formula interactions, and assessment of overall main effects. An accounting of subjects from 4 to 9 mo is shown in Table 1 .

\section{RESULTS}

Three primary measures were analyzed for this study: peak look (i.e. the longest look duration observed during habituation), a behavioral measure taken from the habituation session that is thought to reflect the relative rapidity with which the infant learned or encoded the stimulus (32), the proportion of time spent in SA (averaged across trials), a HR-defined phase of attention, as described above, mean HR during periods of baseline, prelooking, and looking (also averaged across trials; the latter being parsed by the three respective phases of attention described above).

Look duration measures. The analysis for peak look duration (Table 2) showed a significant decline in look duration with age, $F(2,100.912)=22.542, p<0.001$, but no effects of formula. 
Table 1. Available data for study conditions across ages tested

\begin{tabular}{|c|c|c|c|c|c|}
\hline Study group & Outcome & $4 \mathrm{mo}$ & $6 \mathrm{mo}$ & $9 \mathrm{mo}$ & Complete \\
\hline $\begin{array}{l}0.00 \% \text { DHA } \\
0.00 \% \text { ARA }\end{array}$ & $\begin{array}{l}\text { Successful } \\
\text { Fussy } \\
\text { Attrition } \\
\text { Total }\end{array}$ & $\begin{array}{r}24 \\
3 \\
4\end{array}$ & $\begin{array}{r}23 \\
2 \\
6\end{array}$ & $\begin{array}{r}18 \\
5 \\
8\end{array}$ & 15 \\
\hline $\begin{array}{l}0.32 \% \text { DHA, } \\
0.64 \% \text { ARA }\end{array}$ & $\begin{array}{l}\text { Successful } \\
\text { Fussy } \\
\text { Attrition } \\
\text { Total }\end{array}$ & $\begin{array}{r}30 \\
1 \\
1\end{array}$ & $\begin{array}{r}27 \\
1 \\
4\end{array}$ & $\begin{array}{r}23 \\
6 \\
3\end{array}$ & 21 \\
\hline $\begin{array}{l}0.64 \% \text { DHA, } \\
0.64 \% \text { ARA }\end{array}$ & $\begin{array}{l}\text { Successful } \\
\text { Fussy } \\
\text { Attrition } \\
\text { Total }\end{array}$ & $\begin{array}{r}22 \\
4 \\
0\end{array}$ & $\begin{array}{r}23 \\
3 \\
0\end{array}$ & $\begin{array}{r}19 \\
4 \\
3\end{array}$ & 16 \\
\hline $\begin{array}{l}0.96 \% \text { DHA, } \\
0.64 \% \text { ARA }\end{array}$ & $\begin{array}{l}\text { Successful } \\
\text { Fussy } \\
\text { Attrition } \\
\text { Total }\end{array}$ & $\begin{array}{r}28 \\
3 \\
2\end{array}$ & $\begin{array}{r}30 \\
1 \\
2\end{array}$ & $\begin{array}{r}24 \\
4 \\
5\end{array}$ & 20 \\
\hline Sum & $\begin{array}{l}\text { Successful } \\
\text { Fussy } \\
\text { Attrition } \\
\text { Total }\end{array}$ & $\begin{array}{r}104 \\
11 \\
7\end{array}$ & $\begin{array}{r}103 \\
6 \\
13\end{array}$ & $\begin{array}{l}84 \\
19 \\
19\end{array}$ & 72 \\
\hline
\end{tabular}

"Total" reflects the number of infants within each group. Shown are number of infants successfully tested and number lost at each age because of fussiness and attrition/missed appointment. "Complete" are the number of infants within each group that successfully completed session at every age.

Sustained attention. Analyses of the HR-defined phase of SA (also in Table 2) showed significant main effects for both age and formula but no significant interactions. The proportion of time spent in SA declined significantly with age, $F(2,104.743)=6.971, p=0.001$, with SA being significantly higher in the two intermediate doses of DHA (0.32 and $0.64 \%)$ relative to controls $(p=0.035$ and $p=0.005$, respectively). The highest DHA dose $(0.96 \%)$ did not differ from either controls or the two other doses, and the age $\times$ formula interaction did not approach statistical significance.

Infant HR. As expected, infants' HR showed a consistent change with age (all $p$ s $<0.001)$ for every variable tested during the session; overall, HR in beats per minute declined from 146 to 138 to 133 at 4, 6, and 9 mo, respectively. In addition, lower HR was observed consistently for all three supplemented groups, relative to controls. A summary Figure (Fig. 1) shows mean HR for the four groups across baseline, prelooking, and looking (including across each of the three HR-defined phases of attention). At each age, the main effects for formula group ranged from $p<0.05$ to $p<0.01$ (in no case did any two-way interaction attain significance), with pairwise comparisons showing each of the three supplemented groups 5 to 9 beats per minute lower than the unsupplemented controls (Table 3).

\section{DISCUSSION}

Positive effects of postnatal DHA supplementation in term infants are typically seen above $0.20 \%$ total fatty acids as DHA $(14,16)$, but concentrations of DHA in human breast milk can vary well beyond these levels, suggesting that systematic tests of doses at higher levels are desirable. The analyses of data from infant psychophysiological responses and on the quality of attention at 4, 6, and 9 mo showed significant and positive effects of LCPUFA supplementation on the quality of attention in infants from 4 to 9 mo of age.

There were no formula effects or interactions on the peak look variable from habituation. The age effect observed here for this variable has been routinely reported in prior research (33) and is generally attributed to older infants' more rapid processing of stimuli during habituation (26). The lack of any significant effects involving formula here contrasts with prior results indicating sensitivity of look duration to LCPUFA status in preterm infants or to maternal LCPUFA status in full terms $(25,36)$.

The proportion of time spent in SA, which is the phase of attention most strongly linked to active information processing in human infants $(37,38)$, was increased relative to controls in the 0.32 and $0.64 \%$ DHA doses but not at the highest $(0.96 \%)$ dose. The finding of increased SA was observed across all ages at which the measure was taken $(4,6$, and 9 mo). Given that this improvement was not linearly related to DHA dose, we are inclined to posit DHA levels as the source of the effect on SA; because SA at the highest DHA dose was not statistically distinguishable from the two lower doses, however, the contribution of ARA cannot be definitively ruled out, as the power of the study may be less than optimal for comparing individual conditions to one another. Although the effect is attributed to DHA, this would represent the first indication that higher doses of DHA may not incur proportional benefit. In a previous observational study, higher maternal DHA status at birth was found to be associated with lower look duration in later infancy (25); within the context of those results, SA was also observed to be lower in infants from

Table 2. Estimated means and SE (in parentheses) from age $\times$ group mixed model analyses for peak look (expressed in s), and proportions of time spent in SA

\begin{tabular}{|c|c|c|c|c|c|}
\hline Variable & Group & $4 \mathrm{mo}$ & $6 \mathrm{mo}$ & $9 \mathrm{mo}$ & Overall mean \\
\hline \multirow[t]{5}{*}{ Peak look } & $0.00 \%$ DHA, $0.00 \%$ ARA & $33.5(6.94)$ & $27.7(5.21)$ & $13.7(2.27)$ & $25.0 *(3.45)$ \\
\hline & $0.32 \%$ DHA, $0.64 \%$ ARA & $39.0(6.71)$ & $23.9(5.02)$ & $14.8(2.02)$ & $25.9 *(3.31)$ \\
\hline & $0.64 \%$ DHA, $0.64 \%$ ARA & $46.1(7.46)$ & $18.4(5.53)$ & $11.6(2.27)$ & $25.3 *(3.66)$ \\
\hline & $0.96 \%$ DHA, $0.64 \%$ ARA & $33.8(6.70)$ & $22.6(4.86)$ & $18.8(2.05)$ & $25.1 *(3.28)$ \\
\hline & Overall mean $(\mathrm{SE})$ & $38.1 *(3.48)$ & $23.1 \dagger(2.58)$ & $14.7 \ddagger(1.08)$ & $25.3(1.71)$ \\
\hline \multirow[t]{5}{*}{ SA } & $0.00 \%$ DHA, $0.00 \%$ ARA & $0.450(0.043)$ & $0.420(0.042)$ & $0.298(0.045)$ & $0.389 *(0.027)$ \\
\hline & $0.32 \%$ DHA, $0.64 \%$ ARA & $0.528(0.041)$ & $0.470(0.041)$ & $0.412(0.040)$ & $0.470 \dagger(0.025)$ \\
\hline & $0.64 \%$ DHA, $0.64 \%$ ARA & $0.598(0.046)$ & $0.439(0.045)$ & $0.461(0.045)$ & $0.500 \dagger(0.028)$ \\
\hline & $0.96 \%$ DHA, $0.64 \%$ ARA & $0.426(0.041)$ & $0.473(0.039)$ & $0.414(0.040)$ & $0.437 * \dagger(0.025)$ \\
\hline & Overall mean (SE) & $0.500 *(0.021)$ & $0.451 * \dagger(0.021)$ & $0.396 \dagger(0.021)$ & $0.449(0.013)$ \\
\hline
\end{tabular}

Shared symbols $(*, \dagger, \ddagger)$ for group and age overall means denote values that do not statistically differ from one another within that row or column. 
Table 3. Estimated means and SE (in parentheses) from age $\times$ group analyses for infant HR (expressed in bpm) from each segment of habituation trial

\begin{tabular}{|c|c|c|c|c|}
\hline \multirow[b]{2}{*}{ HR during } & \multirow[b]{2}{*}{ Formula condition } & \multicolumn{3}{|c|}{ Age (mo) } \\
\hline & & 4 & 6 & 9 \\
\hline \multirow[t]{4}{*}{ Baseline } & $0.00 \% \mathrm{DHA} / 0.00 \% \mathrm{ARA}$ & $150.2(2.08)$ & $143.0(1.93)$ & $135.0(2.80)$ \\
\hline & $0.32 \%$ DHA/ $0.64 \%$ ARA & $144.4(2.01)$ & $136.0(1.85)$ & $128.0(2.52)$ \\
\hline & $0.64 \% \mathrm{DHA} / 0.64 \% \mathrm{ARA}$ & $149.1(2.24)$ & $137.5(1.85)$ & $137.8(2.82)$ \\
\hline & $0.96 \% \mathrm{DHA} / 0.64 \% \mathrm{ARA}$ & $145.1(2.01)$ & $136.6(1.79)$ & $133.1(2.56)$ \\
\hline \multirow[t]{4}{*}{ Prelook } & $0.00 \% \mathrm{DHA} / 0.00 \% \mathrm{ARA}$ & $155.6(2.20)$ & $146.2(2.06)$ & $139.1(3.16)$ \\
\hline & $0.32 \% \mathrm{DHA} / 0.64 \% \mathrm{ARA}$ & $147.4(2.12)$ & $138.2(1.99)$ & $133.4(2.85)$ \\
\hline & $0.64 \% \mathrm{DHA} / 0.64 \% \mathrm{ARA}$ & $149.6(2.36)$ & $139.6(2.19)$ & $139.1(3.19)$ \\
\hline & $0.96 \%$ DHA/ $0.64 \%$ ARA & $149.2(2.12)$ & $138.8(1.92)$ & $138.4(2.88)$ \\
\hline \multirow[t]{4}{*}{ OR } & $0.00 \% \mathrm{DHA} / 0.00 \% \mathrm{ARA}$ & $159.1(2.35)$ & $147.5(2.27)$ & $142.1(3.59)$ \\
\hline & $0.32 \% \mathrm{DHA} / 0.64 \% \mathrm{ARA}$ & $149.5(2.42)$ & $140.1(2.19)$ & $136.1(3.28)$ \\
\hline & $0.64 \% \mathrm{DHA} / 0.64 \% \mathrm{ARA}$ & $152.9(2.62)$ & $140.0(2.37)$ & $142.3(3.68)$ \\
\hline & $0.96 \%$ DHA/ $0.64 \%$ ARA & $150.4(2.27)$ & $139.5(2.15)$ & $141.1(3.26)$ \\
\hline \multirow[t]{4}{*}{ SA } & $0.00 \% \mathrm{DHA} / 0.00 \% \mathrm{ARA}$ & $149.8(2.18)$ & $141.0(2.78)$ & $132.8(3.12)$ \\
\hline & $0.32 \% \mathrm{DHA} / 0.64 \% \mathrm{ARA}$ & $141.7(2.08)$ & $133.0(2.72)$ & $124.8(2.65)$ \\
\hline & $0.64 \% \mathrm{DHA} / 0.64 \% \mathrm{ARA}$ & $143.7(2.35)$ & $133.1(3.08)$ & $134.3(2.88)$ \\
\hline & $0.96 \% \mathrm{DHA} / 0.64 \%$ ARA & $141.8(2.11)$ & $130.8(2.67)$ & $131.8(2.61)$ \\
\hline \multirow[t]{4}{*}{ AT } & $0.00 \% \mathrm{DHA} / 0.00 \% \mathrm{ARA}$ & $159.6(2.17)$ & $154.5(3.35)$ & $142.5(3.50)$ \\
\hline & $0.32 \% \mathrm{DHA} / 0.64 \% \mathrm{ARA}$ & $151.5(2.05)$ & $142.5(3.10)$ & $134.1(3.19)$ \\
\hline & $0.64 \% \mathrm{DHA} / 0.64 \%$ ARA & $154.1(2.37)$ & $143.4(3.89)$ & $142.5(3.22)$ \\
\hline & $0.96 \%$ DHA/ $0.64 \%$ ARA & $154.2(2.17)$ & $138.7(3.14)$ & $141.8(2.96)$ \\
\hline \multirow[t]{4}{*}{ Postlook } & $0.00 \% \mathrm{DHA} / 0.00 \% \mathrm{ARA}$ & $155.9(6.03)$ & $149.0(5.50)$ & $141.2(4.22)$ \\
\hline & $0.32 \% \mathrm{DHA} / 0.64 \% \mathrm{ARA}$ & $138.1(5.83)$ & $125.4(5.29)$ & $132.3(3.77)$ \\
\hline & $0.64 \% \mathrm{DHA} / 0.64 \% \mathrm{ARA}$ & $151.0(6.49)$ & $140.2(5.84)$ & $141.4(4.23)$ \\
\hline & $0.96 \% \mathrm{DHA} / 0.64 \% \mathrm{ARA}$ & $134.8(5.82)$ & $135.5(5.11)$ & $140.6(3.83)$ \\
\hline
\end{tabular}

Mixed model main effects for formula at each point shown are as follows: baseline, $F(3,104.54)=3.63, p=0.015 ;$ prelooking, $F(3,108.17)=2.85, p=$ $0.041 ; F(3,108.45)=4.13, p=0.008 ; \mathrm{OR}, F(3,105.20)=2.87, p=0.040 ; \mathrm{SA}, F(3,109.02)=3.48, p=0.019 ;$ and $\mathrm{AT}, F(3,90.96)=3.28, p=0.024$.

$\mathrm{OR}$, orienting; AT, attention termination.

high-DHA mothers, which is what one would expect as look duration is reduced. However, in the previous study, DHA status was observed to reduce look duration, in the current one, LCPUFA supplementation did not. We have observed that when look duration is reduced across or within sessions, the proportion of SA is reduced and is generally displaced by OR (39). This appears to be due to the fact that OR represents a latency to decelerate that is fairly constant; in briefer looks, OR takes up a larger proportion of looking and essentially takes this proportion from SA. The increase in SA in the $0.32 \%$ DHA and $0.64 \%$ DHA formula conditions is interpreted as the maintenance of engaged cognitive processing in the context of equal amounts of looking; we see this as a positive benefit of supplementation. It is important to note that the recent results of a large longitudinal study show that infants who show reliable age-related decreases in look duration although maintaining high levels of SA across the first year show better performance on language and cognitive outcomes out to age 4 (40).

LCPUFA supplementation also reduced infants' overall HR when measured during the administration of the visual attention task. The main emphasis of the original study was on dose effects for DHA; it was hypothesized that the three DHAsupplemented groups would vary. The fact that manipulation of DHA dose covaried with the presence of ARA in the formula (i.e. the control formula had neither DHA nor ARA) makes interpretation of this effect complicated, as the reduction in HR (relative to the control group) was statistically equivalent for each of the DHA dose levels. As such, we cannot definitively attribute this effect to the sole action of either of these compounds. The positive effect of LCPUFAs on cardiovascular health in rodents and human adults has been known for some time $(41,42)$, and there have been multiple reports of reductions in HR or increased HR variability as a result of some form of increased n-3 LCPUFA intake $(43,44)$.

Our finding here is also in accord with the results of a previous clinical trial of fish oil supplementation in infants (45) and a preliminary report on an observational study of DHA intake in infants and toddlers (Pivik RT et al. 2008 Resting heart rate in infants and toddlers: variations associated with early infant diet and the omega 3 fatty acid DHA. Forty-Eighth Annual Meeting of the Society for Psychophysiological Research, October 2-4, 2008, Austin, TX, Poster 123), both of which report decreases in HR in relation to DHA status. The pathways through which LCPUFAs influence heart period are not definitively known, although candidate mechanisms include reduced oxygen consumption (46), electrophysiological mediation of the heart rhythm (44), or various forms of autonomic gating originating in the CNS $(47,48)$. The effect of lowering HR in adult populations is viewed as a positive health outcome and has been suggested to impart positive impacts on affective, cognitive, and behavioral outcomes (48). HR declines systematically with age during infancy (31), so the effect may also represent the acceleration of psychophysiological maturation.

In summary, the current findings add further experimental evidence for the positive health and cognitive effects of LCPUFAs in neurodevelopment in human infants. Further research is necessary to definitively dissociate the effects of AA from DHA on HR and SA; the current work may be 
constrained by limited power for these particular variables. Future reports will focus on the long-term implications of the improvements in attention observed with moderate DHA supplementation.

\section{REFERENCES}

1. Clandinin MT, Chappell JE, Leong S, Heim T, Swyer PR, Chance GW 1980 Extra-uterine fatty-acid accretion in infant brain: implications for fatty-acid requirements. Early Hum Dev 4:131-138

2. Martínez M, Mougan I 1998 Fatty acid composition of human brain phospholipids during normal development. J Neurochem 71:2528-2533

3. Farquharson J, Jamieson EC, Abbasi KA, Patrick WJ, Logan RW, Cockburn F 1995 Effect of diet on the fatty-acid composition of the major phospholipids of infant cerebral cortex. Arch Dis Child 72:198-203

4. Makrides M, Neumann MA, Byard RW, Simmer K, Gibson RA 1994 Fatty-acid composition of brain, retina, and erythrocytes in breast-fed and formula-fed infants. Am J Clin Nutr 60:189-194

5. Birch EE, Hoffman DR, Uauy R, Birch DG, Prestidge C 1998 Visual acuity and the essentiality of docosahexaenoic acid and arachidonic acid in the diet of term infants. Pediatr Res 44:201-209

6. Carlson SE, Ford AJ, Werkman SH, Peeples JM, Koo WW 1996 Visual acuity and fatty acid status of term infants fed human milk and formulas with and withou docosahexaenoate and arachidonate from egg yolk lecithin. Pediatr Res 39:882-888

7. Auestad N, Montalto MB, Hall RT, Fitzgerald KM, Wheeler RE, Connor WE, Neuringer M, Connor SL, Taylor JA, Hartmann EE 1997 Visual acuity, erythrocyte fatty acid composition, and growth in term infants fed formulas with long chain polyunsaturated fatty acids for one year. Pediatr Res 41:1-10

8. Jensen CL, Prager TC, Fraley JK, Chen HM, Anderson RE, Heird WC 1997 Effect of dietary linoleic/alpha-linolenic acid ratio on growth and visual function of term infants. J Pediatr 131:200-209

9. Innis SM, Akrabawi SS, Diersen-Schade DA, Dobson MV, Guy DG 1997 Visua acuity and blood lipids in term infants fed human milk or formulae. Lipids 32:63-72

10. Carrié I, Clément M, De Javel D, Francès H, Bourre JM 1999 Learning deficits in first generation $\mathrm{OF} 1$ mice deficient in $(\mathrm{n}-3)$ polyunsaturated fatty acids do not result from visual alteration. Neurosci Lett 266:69-72

11. Wainwright PE, Huang YS, Coscina DV, Levesque S, McCutcheon D 1994 Braineffects and behavioral-effects of dietary n-3 deficiency in mice: a 3-generational study. Dev Psychobiol 27:467-487

12. Stevens LJ, Zentall SS, Abate ML, Kuczek T, Burgess JR 1996 Omega-3 fatty acids in boys with behavior, learning, and health problems. Physiol Behav 59:915-920

13. Willatts P, Forsyth JS 2000 The role of long-chain polyunsaturated fatty acids in infant cognitive development. Prostaglandins Leukot Essent Fatty Acids 63:95-100

14. Agostoni C, Trojan S, Bellu R, Giovannini M 1995 Neurodevelopmental quotient of healthy term infants at 4 months and feeding practice: the role of long-chain polyunsaturated fatty-acids. Pediatr Res 38:262-266

15. Agostoni C, Trojan S, Bellu R, Riva E, Bruzzese MG, Giovannini M 1997 Developmental quotient at 24 months and fatty acid composition of diet in early infancy: a follow up study. Arch Dis Child 76:421-424

16. Birch EE, Garfield S, Hoffman DR, Uauy R, Birch DG 2000 A randomized controlled trial of early dietary supply of long-chain polyunsaturated fatty acids and mental development in term infants. Dev Med Child Neurol 42:174-181

17. Birch EE, Garfield S, Castaneda Y, Hughbanks-Wheaton D, Uauy R, Hoffman D 2007 Visual acuity and cognitive outcomes at 4 years of age in a double-blind, randomized trial of long-chain polyunsaturated fatty acid-supplemented infant formula. Early Hum Dev 83:279-284

18. Makrides M, Neumann MA, Simmer K, Gibson RA 2000 A critical appraisal of the role of dietary long-chain polyunsaturated fatty acids on neural indices of term infants: a randomized, controlled trial. Pediatrics 105:32-38

19. Auestad N, Scott DT, Janowsky JS, Jacobsen C, Carroll RE, Montalto MB, Halter R, Qiu W, Jacobs JR, Connor WE, Connor SL, Taylor JA, Neuringer M, Fitzgerald KM, Hall RT 2003 Visual, cognitive, and language assessments at 39 months: a follow-up study of children fed formulas containing long-chain polyunsaturated fatty acids to 1 year of age. Pediatrics 112:e177-e183

20. Simmer K, Patole SK, Rao SC 2008 Longchain polyunsaturated fatty acid supplementation in infants born at term. Cochrane Database Syst Rev: CD000376

21. Beyerlein A, Hadders-Algra M, Kennedy K, Fewtrell M, Singhal A, Rosenfeld E, Lucas A, Bouwstra H, Koletzko B, von Kries R 2010 Infant formula supplementation with long-chain polyunsaturated fatty acids has no effect on Bayley develop- mental scores at 18 months of age-IPD meta-analysis of 4 large clinical trials. J Pediatr Gastroenterol Nutr 50:79-84

22. Colombo J 2002 Infant attention grows up: the emergence of a developmental cognitive neuroscience perspective. Curr Dir Psychol Sci 11:196-200

23. Bornstein MH, Sigman MD 1986 Continuity in mental development from infancy. Child Dev 57:251-274

24. Colombo J 1993 Infant Cognition: Predicting Later Intellectual Functioning. Sage Publications, Newbury Park, pp. 30-81

25. Colombo J, Kannass KN, Shaddy DJ, Kundurthi S, Maikranz JM, Anderson CJ, Blaga OM, Carlson SE 2004 Maternal DHA and the development of attention in infancy and toddlerhood. Child Dev 75:1254-1267

26. Colombo J, Mitchell DW 2009 Infant visual habituation. Neurobiol Learn Mem 92:225-234

27. Casey BJ, Richards JE 1988 Sustained visual-attention in young infants measured with an adapted version of the visual preference paradigm. Child Dev 59:1514-1521

28. McLennan PL, Owen AJ, Slee EL, Theiss ML 2007 Myocardial function, ischaemia and $n-3$ polyunsaturated fatty acids: a membrane basis. J Cardiovasc Med (Hagerstown) 8:S15-S18

29. Christensen JH, Schmidt EB 2007 Autonomic nervous system, heart rate variability and n-3 fatty acids. J Cardiovasc Med (Hagerstown) 8:S19-S22

30. Birch EE, Carlson SE, Hoffman DR, Fitzgerald-Gustafson KM, Fu VL, Drover JR, Castaneda YS, Minns L, Wheaton DK, Mundy D, Marunycz J, Diersen-Schade DA 2010 The DIAMOND (DHA Intake And Measurement Of Neural Development) Study: a double-masked, randomized controlled clinical trial of the maturation of infant visual acuity as a function of the dietary level of docosahexaenoic acid. Am J Clin Nutr 91:848-859

31. Colombo J, Shaddy DJ, Richman WA, Maikranz JM, Blaga OM 2004 The developmental course of habituation in infancy and preschool outcome. Infancy 5:1-38

32. Colombo J, Mitchell DW, O'Brien M, Horowitz FD 1987 The stability of visua habituation during the first year of life. Child Dev 58:474-487

33. Colombo J, Mitchell DW 1990 Individual differences in early visual attention: fixation time and information processing. In: Colombo J, Fagen J (eds) Individual Differences in Infancy: Reliability, Stability, Prediction. Lawrence Erlbaum Associates, Hillsdale, NJ, pp 193-227

34. Colombo J, Horowitz FD 1985 A parametric study of the infant control procedure. Infant Behav Dev 8:117-121

35. Richards JE 1985 The development of sustained visual-attention in infants from 14 to 26 weeks of age. Psychophysiology 22:409-416

36. Carlson SE, Werkman SH 1996 A randomized trial of visual attention of preterm infants fed docosahexaenoic acid until two months. Lipids 31:85-90

37. Richards JE 1987 Infant visual sustained attention and respiratory sinus arrhythmia. Child Dev 58:488-496

38. Colombo J, Richman WA, Shaddy DJ, Greenhoot AF, Maikranz JM 2001 Heart rate-defined phases of attention, look duration, and infant performance in the paired-comparison paradigm. Child Dev 72:1605-1616

39. Colombo J, Shaddy DJ, Anderson CJ, Gibson LJ, Blaga OM, Kannass KN 2010 What habituates in infant visual habituation? A psychophysiological analysis. Infancy 15:107-124

40. Colombo J, Shaddy DJ, Blaga OM, Anderson CJ, Kannass KN, Richman WA 2009 Early attentional predictors of vocabulary in childhood. In: Colombo J, McCardle P, Freund L (eds) Infant Pathways to Language: Methods, Models, and Research Directions. Lawrence Erlbaum Associates, New York, NY, pp 143-167

41. Calder PC 2004 n-3 fatty acids and cardiovascular disease: evidence explained and mechanisms explored. Clin Sci 107:1-11

42. von Schacky C 2004 Omega-3 fatty acids and cardiovascular disease. Curr Opin Clin Nutr Metab Care 7:131-136

43. Mozaffarian D, Stein PK, Prineas RJ, Siscovick DS 2008 Dietary fish and omega-3 fatty acid consumption and heart rate variability in US adults. Circulation 117:11301137

44. Mozaffarian D, Prineas RJ, Stein PK, Siscovick DS 2006 Dietary fish and n-3 fatty acid intake and cardiac electrocardiographic parameters in humans. J Am Coll Cardiol 48:478-484

45. Lauritzen L, Christensen JH, Damsgaard CT, Michaelsen KF 2008 The effect of fish oil supplementation on heart rate in healthy Danish infants. Pediatr Res 64:610-614

46. Peoples GE, McLennan PL, Howe PR, Groeller H 2008 Fish oil reduces heart rate and oxygen consumption during exercise. J Cardiovasc Pharmacol 52:540-547

47. Gustafson KM, Colombo J, Carlson SE 2008 Docosahexaenoic acid and cognitive function: is the link mediated by the autonomic nervous system? Prostaglandins Leukot Essent Fatty Acids 79:135-140

48. Hibbeln JR, Ferguson TA, Blasbalg TL 2006 Omega-3 fatty acid deficiencies in neurodevelopment, aggression and autonomic dysregulation: opportunities for intervention. Int Rev Psychiatry 18:107-118 